\section{Use of Commercially Available Pollenizers for Optimizing Triploid Watermelon Production}

\author{
Peter J. Dittmar ${ }^{1,3}$, David W. Monks², and Jonathan R. Schultheis ${ }^{2}$ \\ Department of Horticultural Science, North Carolina State University, \\ Kilgore Hall, Campus Box 7609, Raleigh, NC 27695-7609
}

Additional index words. Citrullus lanatus, pollination, seedless, diploid, interplant, timing, honey bee, plant establishment, spacing

\begin{abstract}
An experiment was conducted during 2005 and 2006 in Kinston, NC, with the objective of maximizing triploid watermelon [Citrullus lanatus (Thunb.) Matsum. and Nak.] fruit yield and quality by optimizing the choice and use of pollenizers. Treatments were pollenizer cultivars planted singly ['Companion', 'Super Pollenizer 1' ('SP1'), 'Summer Flavor 800' ('SF800'), and 'Mickylee'] or in pairs ('Companion' + 'SP1', 'Companion' + 'SF800', and 'SP1' + 'SF800'). All pollenizers from these seven treatments were interplanted with the triploid cultivar Tri-X-313. Planting arrangement was compared by establishing 'SF800' in a hill versus an interplanted field arrangement. Effect of pollenizer establishment timing on triploid fruit yields and quality was evaluated by establishing 'SP1' 3 weeks after planting and comparing it with the establishment of 'SP1' at the time of triploid plant establishment. Finally, a triploid planting with no pollenizer (control) was included to determine pollen movement. Fruit yield from the control was $22 \%$ or less of yield of the other treatments containing a pollenizer and less than $10 \%$ in the initial or early harvests. Pollen movement was minimal among plots and differences in yield and fruit quality could be attributed to pollenizer treatment. In 2005, the use of 'Companion', 'SP1', or 'Mickylee' as pollenizers produced similar total yields, whereas 'SF800' produced the lowest yield. In 2005, 'Companion' produced more large fruit than the other individual pollenizer treatments. Combining the pollenizers generally did not enhance triploid yields or quality. Interplanting of pollenizers consistently resulted in greater yield compared with the hill system. Late planting of 'SP1' increased the incidence of hollow heart in the marketable fruit and decreased yield compared with simultaneously planting 'SP1' and triploid plants. Thus, selection of pollenizer, planting arrangement, and time of pollenizer establishment are all important considerations to optimizing triploid yield and quality.
\end{abstract}

Triploid (seedless) watermelons have increased in popularity and compose three fourths of the watermelon production in the United States (U.S. Department of Agriculture, Economic Research Service, 2005). Triploid watermelons produce nonviable pollen and require a nearby diploid (seeded) watermelon plant to supply viable pollen (Kihara, 1951; Robinson and Decker-Walters, 1997; Rubatzky and Yamaguchi, 1997).

Pollenizer selection affects triploid fruit quantity, quality, and timing of harvest. Iceboxtype watermelons that produce flowers early in the season result in an early harvest of triploid fruit, and later flowering cultivars will result in a later triploid fruit harvest (Maynard and Elmstrom, 1990). 'Millionaire', a triploid watermelon, produced more large fruit, marketable fruit, and total yields with 'Crimson Sweet' as the pollenizer compared with 'Fiesta'

\footnotetext{
Received for publication 2 Nov. 2009. Accepted for publication 14 Feb. 2010.

Technical assistance by W. Bradfred Thompson and statistical assistance from Joy Smith and Dr. William Swallow are greatly appreciated.

${ }^{1}$ Graduate Research Assistant.

${ }^{2}$ Professor.

${ }^{3}$ To whom reprint requests should be addressed; e-mail pjdittma@ncsu.edu.
}

(Fiacchino and Walters, 2003). Furthermore, 'Fiesta' as a pollenizer resulted in 'Millionaire' producing more fruit having hollow hearts. The use of 'Companion' and 'Pinnacle' as pollenizers produced less total weight of 'Tri-X-313' triploid watermelon than the other pollenizer treatments; however, there were no differences in total fruit or hollow heart (Freeman et al., 2007a). 'SP1' pollenizer produced more yield of 'Sugarheart' triploid fruit than 'Mickylee'

Pollenizer plants are planted in triploid production fields using one of three primary arrangements: 1) separate dedicated rows; 2) hill-planted; or 3) interplanted. The separate dedicated row planting arrangement has a row of pollenizers planted the length of the field. The next two to four rows are planted with triploid watermelons the length of the field and the row pattern is repeated. In the hill-planting method, two to four triploid plants are transplanted; then, a pollenizer plant is transplanted in the next hill, and this pattern is repeated the length of the field. In the interplanted arrangement, triploid plants are transplanted in each hill the entire length of the field. After every second to fourth triploid plant, a pollenizer is planted between triploid plant hills in the same row. This pattern is repeated the length of the field. (Freeman et al., 2007b).
The objective of this research was to optimize the production of triploid watermelon by comparing the use of commercially available pollenizers. Individual pollenizers were compared as well as combinations of two pollenizers. Planting arrangement was tested by comparing interplanted with hill-planted treatments, and delayed pollenizer planting was evaluated for triploid production and quality.

\section{Materials and Methods}

Cultural practices. Plants were transplanted on 18 May 2005 and 15 May 2006 at the Cunningham Research Station, Kinston, $\mathrm{NC}$, in a Norfolk sandy loam (fine loamy, siliceous, thermic, typic Kandiudults) soil. Black polyethylene mulch ( $32 \mu \mathrm{m}$ thick, $1.5 \mathrm{~m}$ wide; Reddick Fumigants, Williamston, NC) was laid on $0.9-\mathrm{m}$ wide raised beds with $2.0 \mathrm{~m}$ between row centers. Before transplanting, $616 \mathrm{~kg} \cdot \mathrm{ha}^{-1}$ of fertilizer $(10 \mathrm{~N}-20 \mathrm{P}-20 \mathrm{~K})$ was broadcast-applied; rows were then bedded and fumigated with 1,3-dichloropropene (Telone II; Dow AgriSciences, Indianapolis, IN) at 4.7 $\mathrm{L} \cdot \mathrm{ha}^{-1}$ just before black polyethylene mulch and drip tubing were placed in the field. Triploid plants were transplanted with $0.9 \mathrm{~m}$ in-row spacing. To avoid pest resistance, pesticide chemistries were applied on a rotational basis based on North Carolina cultural recommendations (Sanders, 2004, 2005). Care was taken to avoid applications during the morning when bee activity was greatest. For all years, four honeybee hives/ha were placed in the center of the field at the end of the rows. In 2006, two hives had less than optimal bee populations and eventually had few or no bees in the hives as the production season progressed. Six weeks after transplanting, two new hives were placed in the same location of the field.

Treatments. Each pollenizer treatment included one pollenizer cultivar or a combination of two pollenizer cultivars. The control treatment contained no pollenizer and was included to determine the amount of pollen movement between treatment areas and overall effectiveness of the field design. The individual and combination pollenizer treatments were interplanted between the second and third triploid plants and then after every third plant in the treatment area for a 1:3 (pollenizer:triploid) ratio. All pollenizer treatments except one ('SP1' late planting) were transplanted the same time as the triploid transplants. The following were used exclusively as single pollenizer treatments: 'Companion' (Seminis Vegetable Seed, Oxnard, CA), 'Mickylee' (Willhite Seed, Poolville, TX), 'Summer Flavor 800' (SF800) (Abbott \& Cobb Inc., Feasterville, PA), and 'Super Pollenizer 1' ('SP1') (Syngenta, Boise, ID). Combinations of 'Companion' + 'SF800', 'Companion' + 'SP1', and 'SF800' + 'SP1' were also included as treatments. A second individual 'SF800' treatment was hill-planted after every third triploid plant. In addition to planting 'SP1' on the same date as the triploid plants, a second individual 'SP1' treatment was included in which the pollenizer plants 
were transplanted in the field 3 weeks after the triploid plants. This treatment was used to improve fruit set and quality by preventing crown fruit set because hollow heart occurs more often in the crown fruit set (Maynard and Hopkins, 1999).

Experiment design. Treatments were arranged in a randomized complete block design with four replications. Plots were four rows wide (Fig. 1). At the beginning of each row and between treatment areas was an 11.9-m border of 'Tri-X-Palomar' (Syngenta) plants with no pollenizer. After the border was the treatment plot planted with the pollenizer, $11.0 \mathrm{~m}$ long. The outside two rows of the plot were planted with 'Tri-X-Palomar' plants and the center two rows were planted with 'Tri-X313' plants (Syngenta). Following the plot was $11.9 \mathrm{~m}$ of 'Tri-X-Palomar' and a $1.5-\mathrm{m}$ break (no plants) to designate plots. The plot, border, and break were repeated the length of the row. Next to the four row plots on either side were two border rows of 'Tri-X-Palomar' plants without pollenizer plants. On either side of these two row borders was a 6.1-m drive row for spray and harvest equipment.
Harvest and statistical analysis. Fruit were harvested from 'Tri-X-313' plants twice in 2005 (27 July and 4 Aug.) and four times in 2006 (17 July, 24 July, 3 Aug., and 10 Aug.). All fruit were weighed and 15 randomly selected marketable fruit from each plot were cut in half longitudinally to score for hollow heart. Five of the 15 fruit were measured for soluble solids with a handheld refractometer (Model NT-032ATC; Q-A Supplies, LLC, Norfolk, VA) by removing a sample of flesh from the center of the mesocarp. Hollow heart was rated from 0 (none) to 4 (severe). The approximate measurements $(\mathrm{cm})$ for each hollow heart rating were: width less than 0.6, depth less than 1.3 (rating 1); $0.6<$ width less than $3.3,1.3<$ depth less than 5.1 (rating 2); width 3.3 or greater, depth greater than 5.1 (rating 3 ); width 3.3 or greater, depth 10.2 or greater (rating 4) (Fig. 2). Fruits rated 0 through 2 were considered to be marketable. If the rating was a 3 or 4 , the fruits were considered nonmarketable and considered as having damage or serious damage hollow heart, respectively (U.S. Department of Agriculture, 2006). All data were analyzed using

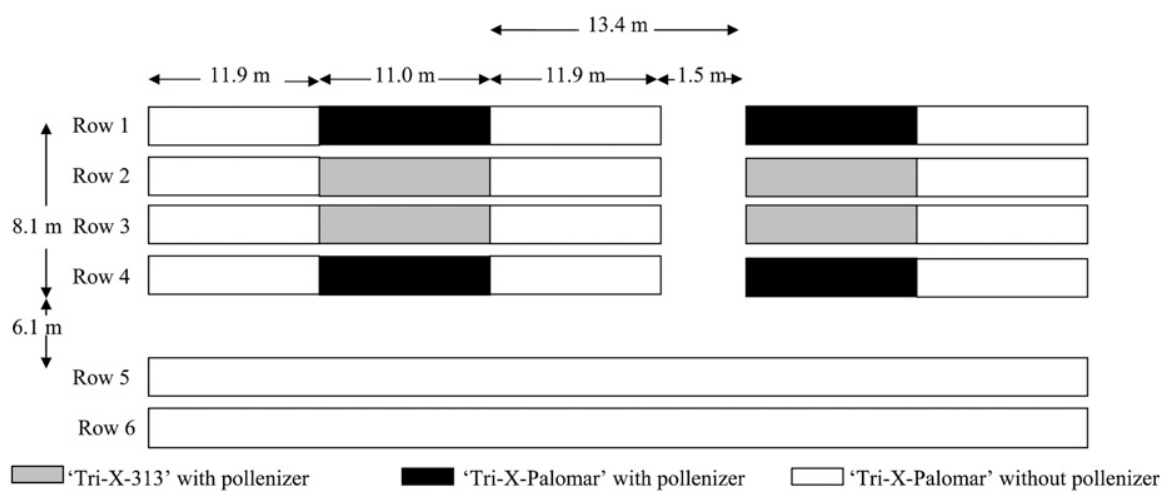

Fig. 1. Experimental design of treatment area and borders of two plots. A plot consisted of four rows. The beginning of each row had a border of 'Tri-X-Palomar' plants planted without pollenizer plants. After the border, outer plot rows were planted with 'Tri-X-Palomar' plants and the designated treatment pollenizer plants and the center two plot rows were planted with 'Tri-X-313' plants and the designated treatment pollenizer plants. Following the treatment area was a second border of 'Tri-X-Palomar' plants without pollenizer plants and an unplanted break. The treatment area, second border, and break were repeated the length of the field.

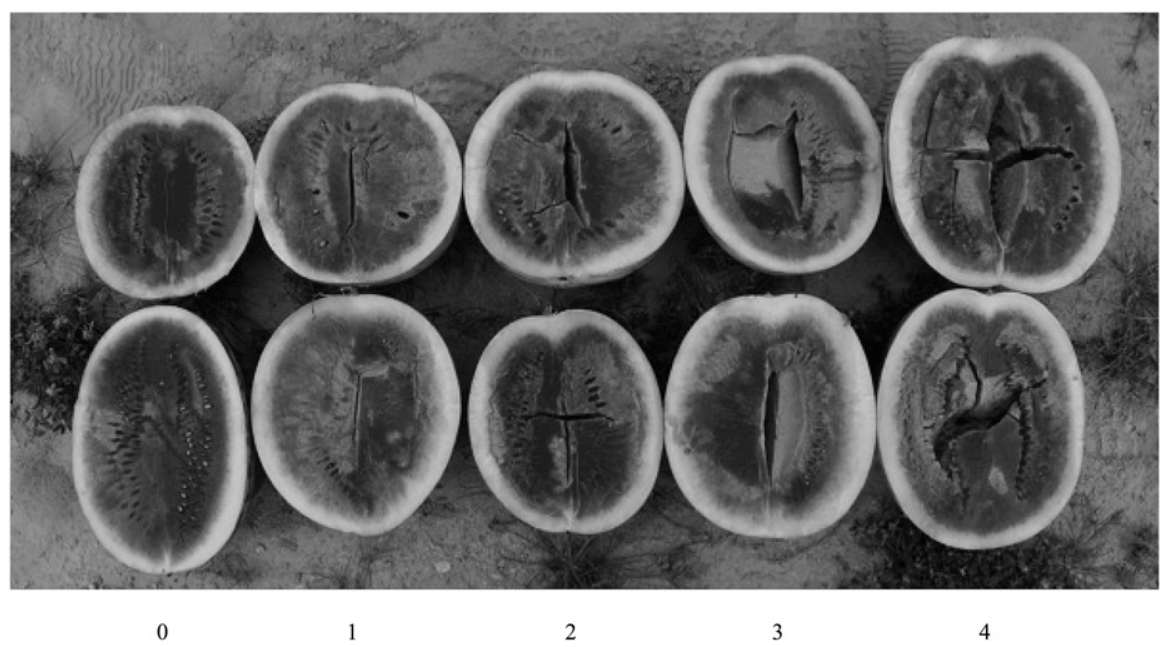

Fig. 2. Hollow heart rating of market weight triploid watermelon rated 0 (none) to 4 (severe).
GLM, and means were separated with least significant difference $(P<0.05)$ and contrasts (Version 9.1.3; SAS Institute, 2002). Year variable was significant for all variables, so years are presented separately.

\section{Results}

Individual pollenizer treatments. Total fruit weight or number was calculated as the cumulative weight or number of fruit $2.3 \mathrm{~kg}$ or greater, whereas marketable fruit weight or number was calculated as the cumulative weight or number of all fruit $3.6 \mathrm{~kg}$ or greater. In 2005, the best total and marketable yield of 'Tri-X-313' was obtained from 'Companion', 'SP1', and 'Mickylee' treatments (Table 1). The use of 'SF800' interplanted resulted in lower triploid yields (74.4 MT/ha) than the other individual pollenizer treatments. In 2006, the 'Companion', 'Mickylee', 'SP1', and 'SF800' interplanted treatments had similar yields.

Triploid fruit were separated into three weight classes: small (less than $3.6 \mathrm{~kg}$ ), medium (between 3.6 and $7.3 \mathrm{~kg}$ ), and large (greater than $7.3 \mathrm{~kg}$ ) (Table 2). In 2005 and 2006 , there were no differences in the weight of small fruit as a result of a single pollenizer treatment (data not shown). In 2005, plots with 'Mickylee' and 'SP1' produced more medium fruit than those with 'Companion' (Table 2). The use of 'Companion' resulted in greater yield of large fruit than the other single pollenizer treatments. In 2006, the 'Mickylee' and 'SP1' treatment had greater yields of medium fruit (55.8 and 50.4 MT/ha, respectively) than the 'Companion' treatment (30.3 MT/ha). Although 'Companion' produced the greatest weight of large fruit (58.2 MT/ha), it only differed from the 'SF800' interplanted treatment $(30.5 \mathrm{MT} / \mathrm{ha})$. Large fruit yields resulting from the 'Mickylee' and 'SP1' treatments were between 'Companion' and 'SF800' treatments. For both years, the largest individual fruits were obtained when the 'Companion' pollenizer treatment was used, whereas 'Mickylee', 'SP1', and 'SF800' treatments produced fruit of similar size (Table 2).

Considering the four individual pollenizer treatments in 2005, greater yields were obtained at the first harvest rather than in the second harvest (data not shown). For the first harvest, the highest yields were observed with 'Companion' (80.7 MT/ha), whereas the lowest yields were obtained with 'SF800' interplanted (56.8 MT/ha). Yields from the second harvest did not differ between the individual pollenizer treatments (data not shown). In 2006, yields for the four individual interplanted pollenizer treatments for the first harvest were similar (Table 1). In the second harvest of 2006, the use of 'Companion' as a pollenizer yielded the greatest marketable triploid fruit weight, $39.9 \mathrm{MT} / \mathrm{ha}$, whereas treatments containing 'SP1', 'Mickylee', and 'SF800' yielded similar marketable fruit weight in the second harvest (data not shown). Yields for the third and fourth harvests were not different among the single pollenizer treatments (data not shown). 
Table 1. Effect of different diploid watermelon pollenizer treatments on total and marketable fruit weights of 'Tri-X-313'.

\begin{tabular}{|c|c|c|c|c|c|c|}
\hline \multirow[b]{2}{*}{ Treatment } & \multicolumn{2}{|c|}{$\begin{array}{l}\text { First harvest wt } \\
(\mathrm{MT} / \mathrm{ha})^{\mathrm{y}}\end{array}$} & \multicolumn{2}{|c|}{$\begin{array}{l}\text { Total fruit wt } \\
(\mathrm{MT} / \mathrm{ha})^{\mathrm{x}}\end{array}$} & \multicolumn{2}{|c|}{$\begin{array}{l}\text { Market fruit wt } \\
(\mathrm{MT} / \mathrm{ha})\end{array}$} \\
\hline & 2005 & 2006 & 2005 & 2006 & 2005 & 2006 \\
\hline 1. Companion & $80.7 \mathrm{a}^{\mathrm{w}}$ & $23.2 \mathrm{a}$ & $91.4 \mathrm{a}$ & $89.1 \mathrm{bc}$ & $89.8 \mathrm{a}$ & $88.4 \mathrm{ab}$ \\
\hline 2. Mickylee & $68.1 \mathrm{bc}$ & $23.0 \mathrm{a}$ & $86.2 \mathrm{a}$ & $100.5 \mathrm{abc}$ & $85.2 \mathrm{ab}$ & $95.5 \mathrm{ab}$ \\
\hline 3. Super Pollenizer 1 (SP1) & $69.3 \mathrm{bc}$ & $15.9 \mathrm{ab}$ & $89.0 \mathrm{a}$ & $97.4 \mathrm{abc}$ & $87.5 \mathrm{ab}$ & $93.2 \mathrm{ab}$ \\
\hline $\begin{array}{l}\text { 4. Summer Flavor } 800 \text { (SF800) } \\
\text { (interplanted) }\end{array}$ & $56.8 \mathrm{~d}$ & $11.9 \mathrm{abc}$ & $74.4 \mathrm{~b}$ & $75.9 \mathrm{c}$ & $71.9 \mathrm{c}$ & $72.9 \mathrm{~b}$ \\
\hline 5. Companion and SP1 & $71.7 \mathrm{ab}$ & $23.0 \mathrm{a}$ & $87.3 \mathrm{a}$ & $115.7 \mathrm{a}$ & $86.4 \mathrm{ab}$ & $110.9 \mathrm{a}$ \\
\hline 6. Companion and SF800 & $62.1 \mathrm{~cd}$ & $11.8 \mathrm{abc}$ & $82.1 \mathrm{ab}$ & $110.2 \mathrm{ab}$ & $81.5 \mathrm{~b}$ & $105.2 \mathrm{ab}$ \\
\hline 7. SF800 and SP1 & $57.1 \mathrm{~d}$ & $11.6 \mathrm{abc}$ & $83.0 \mathrm{ab}$ & $97.8 \mathrm{abc}$ & $81.6 \mathrm{~b}$ & $94.2 \mathrm{ab}$ \\
\hline 8. SP1 (late planting) & $37.6 \mathrm{e}$ & $7.1 \mathrm{bc}$ & $52.5 \mathrm{c}$ & $105.6 \mathrm{ab}$ & $48.4 \mathrm{~d}$ & $101.8 \mathrm{a}$ \\
\hline 9. SF800 (hill-planted) & $36.6 \mathrm{e}$ & $8.9 \mathrm{bc}$ & $57.2 \mathrm{c}$ & $75.7 \mathrm{c}$ & $45.5 \mathrm{~d}$ & $72.8 \mathrm{~b}$ \\
\hline 10. Control & $3.2 \mathrm{f}$ & $0.7 \mathrm{c}$ & $11.8 \mathrm{~d}$ & $14.9 \mathrm{~d}$ & $9.7 \mathrm{e}$ & $14.9 \mathrm{c}$ \\
\hline LSD $(0.05)$ & 9.2 & 12.0 & 8.7 & 26.5 & 8.2 & 26.0 \\
\hline Contrasts & & & & & & \\
\hline $\begin{array}{l}\text { Pollenizer }(1,2,3,4,5,6,7,8,9) \\
\text { versus no pollenizer }(10)\end{array}$ & $* * * \mathrm{v}$ & $* *$ & $* * *$ & $* * *$ & $* * *$ & $* * *$ \\
\hline $\begin{array}{l}\text { Individual }(1,3,4) \text { versus } \\
\text { combined }(5,6,7)\end{array}$ & NS & NS & NS & $* *$ & NS & $*$ \\
\hline $\begin{array}{l}\text { Mickylee (2) versus combined } \\
\quad(5,6,7)\end{array}$ & NS & NS & NS & NS & NS & NS \\
\hline $\begin{array}{l}\text { Companion alone }(1) \text { versus } \\
\text { Companion combined }(5,6)\end{array}$ & $* *$ & NS & NS & $*$ & NS & NS \\
\hline $\begin{array}{l}\text { SP1 alone }(3) \text { versus SP1 } \\
\text { combined }(5,7)\end{array}$ & NS & NS & NS & NS & NS & NS \\
\hline $\begin{array}{l}\text { SF800 alone }(4) \text { versus SF800 } \\
\text { combined }(6,7)\end{array}$ & NS & NS & $*$ & $*$ & $* *$ & $*$ \\
\hline $\begin{array}{l}\text { SF800; Interplanted (4) versus } \\
\text { hill-planted (9) }\end{array}$ & $* * *$ & $*$ & $* * *$ & NS & $* * *$ & NS \\
\hline $\begin{array}{l}\text { SP1; } 0(3) \text { versus } 3 \text { weeks after } \\
\text { triploid planting }(8)\end{array}$ & $* * *$ & NS & $* * *$ & NS & $* * *$ & NS \\
\hline
\end{tabular}

${ }^{2}$ Interior fruit quality such as hollow heart was not considered with regard to marketable yields.

${ }^{y}$ Cumulative weight of all fruit harvested.

${ }^{\mathrm{x}}$ Cumulative weight of fruit greater than $3.6 \mathrm{~kg}$.

wAny two means within a column followed by the different letters are significantly different.

${ }^{\mathrm{NS}}, *, * *, * *$ Nonsignificant or significant at the $5 \%, 1 \%$, and $0.01 \%$, respectively.

LSD $=$ least significant difference.

Pollenizer treatment influenced the incidence of hollow heart. In 2005, the 'SF800' interplanted pollenizer treatment had less than $3 \%$ fruit with hollow heart compared with 24.4\% using 'Companion' alone (Table 3). Fruit produced with 'Mickylee' and 'SP1' did not differ for incidence of hollow heart in the other single interplanted pollenizer treatments. In 2006, the percentage of marketable fruit with minimal or no hollow heart was similar among the four individual interplanted pollenizer treatments and ranged from $77.8 \%$ to $93.3 \%$.

'Companion' alone versus combined with other pollenizers. For both years, combining 'Companion' with either 'SF800' or 'SP1' did not improve total and marketable triploid yields compared with using 'Companion' alone (Table 1). However, total yields were enhanced in 2006 when 'Companion' was combined with 'SF800' or 'SP1'.

Combining an additional pollenizer with 'Companion' increased the yield of small fruit in 2006, but not in 2005 (data not shown). In 2005 and 2006, combining 'SP1' or 'SF800' with 'Companion' increased the yield of medium fruit compared with 'Companion' alone (Table 2). There was a decrease in large fruit yield when pollenizers were combined with 'Companion' in 2005 but not 2006. The higher quantities of medium fruit in 2005 likely resulted in reduced fruit size in the 'Companion' + 'SP1' and 'Companion' + 'SF800' treatments compared with the average individual fruit size produced only with 'Companion'. In 2006, the yield of large fruit and individual fruit weight were unaffected when 'Companion' was combined with the other pollenizers.

Marketable yields for the various harvests were affected by the pollenizer(s) used (Table 1). Combining 'Companion' with another pollenizer decreased triploid yields in the first harvest of 2005 at least $9 \mathrm{MT} / \mathrm{ha}$ compared with using only 'Companion' as the pollenizer. 'Companion' combined with 'SF800' decreased yields by $18.6 \mathrm{MT} / \mathrm{ha}$ compared with using 'Companion' alone. Yields in the second harvest in 2005 were unaffected when either 'SF800' or 'SP1' was combined with 'Companion' (data not shown). In 2006, the combination of a pollenizer with 'Companion' provided no differences in yield of marketable fruit, except the last harvest in which triploid yields were increased by combining 'Companion' with another pollenizer.

In 2005, combining 'SP1' with 'Companion' increased marketable yield $22 \%$ compared with using 'Companion' alone (Table 1). Marketable yield was increased by reducing the incidence and severity of hollow heart. In 2006, the pollenizer treatment had no effect on the percentage of marketable fruit.

'SF800' alone versus combined with other pollenizers. In 2005 and 2006, combining 'SF800' with 'SP1' or 'Companion' increased total and marketable yield compared with 'SF800' interplanted (Table 1). 'SP1' or 'Companion' was combined with 'SF800' and had greater total and marketable yield compared with 'SF800' alone interplanted. The addition of these pollenizers with 'SF800' consistently resulted in a gain of 8 to $34 \mathrm{MT} / \mathrm{ha}$. The combination of 'Companion' or 'SP1' with 'SF800' had no effect on small or medium fruit yields during either year (Table 2). In 2006, yields of large fruit were increased when a pollenizer was combined with 'SF800'. 'Companion' with 'SF800' improved the yield of large fruit (57.2 MT/ha) compared with 'SF800' alone (30.5 MT/ha) (Table 2). Medium fruit yield both years and large fruit yield in 2005 were not different from combining 'SP1' and 'Companion' with 'SF800' and 'SF800' alone (interplanted) (Table 2). In 2006, combining 'SF800' with 'SP1' or 'Companion' increased large fruit yield compared with 'SF800' alone (interplanted). Combining 'SF800' with 'SP1' or 'Companion' had no effect on yield in individual harvests or on percentage of marketable fruit affected by hollow heart (Tables 1 and 3).

'SP1' alone versus combined with other pollenizers. No differences in fruit weight classes (Table 2), individual fruit size, or percent hollow heart (Table 3 ) occurred when 'SP1' was used alone or in combination with other pollenizers. Furthermore, for both years, there were no differences in total and marketable fruit yields when 'SP1' was used as a pollenizer alone or in combination with 'Companion' or 'SF800' (Table 1).

'SF800'; interplanted versus hill-planted. In 2005, total and marketable yields of triploid fruits from the interplanted 'SF800' were greater than the hill-planted (Table 1), although these differences were not detected in 2006. In 2005, when 'SF800' was hill-planted, less large triploid watermelon fruit yield resulted compared with the interplanted treatment (Table 2). The weight of the individual 'Tri-X-313' fruit did not differ between the two treatments.

In the first harvest of both years, fruit obtained from the hill planting was less than the interplanted treatment (Table 1). The percentage of marketable fruit with no or minimal hollow heart was similar between the hill-planted and interplanted 'SF800' treatments (Table 3 ).

'SP1'; 0 versus 3 weeks after triploid planting. In 2005, planting 'SP1' 3 weeks later reduced the yield of total and marketable triploid fruit nearly $40 \mathrm{MT} /$ ha compared with planting 'SP1' at the same time as the triploid plants (Table 1). In 2005, the earlier planting of 'SP1' resulted in $\approx 20 \mathrm{MT} /$ ha more medium fruit and large fruit than with the late 'SP1' planting (Table 2). However, no differences were detected in 2006 for total and marketable fruit weight (Table 1) as well as individual weight classes and fruit size (Table 2).

The first harvest of 2005 had greater yields when 'SP1' was planted the same time as the triploid plants $(69.3 \mathrm{MT} / \mathrm{ha})$ than with the later planting of 'SP1' (37.6 MT/ha) (Table 1), although by the second harvest, 
Table 2. Effect of different diploid watermelon pollenizer treatments on the weight class distribution of the total fruit weight of 'Tri-X-313'.

\begin{tabular}{|c|c|c|c|c|c|c|}
\hline \multirow[b]{3}{*}{ Treatment } & \multicolumn{4}{|c|}{ Total wt (MT/ha) } & & \\
\hline & \multicolumn{2}{|c|}{ Medium $^{\mathrm{y}}$} & \multicolumn{2}{|c|}{ Large $^{\mathrm{x}}$} & \multicolumn{2}{|c|}{ Indvidual wt $(\mathrm{kg})$} \\
\hline & 2005 & 2006 & 2005 & 2006 & 2005 & 2006 \\
\hline 1. Companion & $31.1 \mathrm{~cd}^{\mathrm{w}}$ & $30.3 \mathrm{c}$ & $58.7 \mathrm{a}$ & $58.2 \mathrm{a}$ & $7.5 \mathrm{a}$ & $7.7 \mathrm{a}$ \\
\hline 2. Mickylee & $44.7 \mathrm{ab}$ & $55.8 \mathrm{a}$ & $40.4 \mathrm{~b}$ & $39.7 \mathrm{abc}$ & $6.7 \mathrm{~b}$ & $6.1 \mathrm{~b}$ \\
\hline 3. Super Pollenizer 1 (SP1) & $47.5 \mathrm{a}$ & $50.4 \mathrm{ab}$ & $40.0 \mathrm{~b}$ & $42.8 \mathrm{abc}$ & $6.6 \mathrm{bc}$ & $6.4 \mathrm{~b}$ \\
\hline $\begin{array}{l}\text { 4. Summer Flavor (SF800) } \\
\text { (interplanted) }\end{array}$ & $37.4 \mathrm{abcd}$ & $42.4 \mathrm{abc}$ & $34.5 \mathrm{~b}$ & $30.5 \mathrm{~cd}$ & $6.5 \mathrm{bc}$ & $6.3 \mathrm{~b}$ \\
\hline 5. Companion and SP1 & $45.4 \mathrm{ab}$ & $49.7 \mathrm{ab}$ & $41.1 \mathrm{~b}$ & $61.2 \mathrm{a}$ & $6.9 \mathrm{~b}$ & $6.9 \mathrm{ab}$ \\
\hline 6. Companion and SF800 & $41.1 \mathrm{abc}$ & $48.0 \mathrm{ab}$ & $40.4 \mathrm{~b}$ & $57.2 \mathrm{ab}$ & $7.0 \mathrm{~b}$ & $7.0 \mathrm{ab}$ \\
\hline 7. SF800 and SP1 & $43.6 \mathrm{ab}$ & $47.4 \mathrm{ab}$ & $37.9 \mathrm{~b}$ & $46.8 \mathrm{abc}$ & $6.7 \mathrm{~b}$ & $6.4 \mathrm{~b}$ \\
\hline 8. SP1 (late planting) & $27.5 \mathrm{~d}$ & $48.6 \mathrm{ab}$ & $20.8 \mathrm{c}$ & $53.3 \mathrm{ab}$ & $6.2 \mathrm{bc}$ & $7.0 \mathrm{ab}$ \\
\hline 9. SF800 (hill-planted) & $35.3 \mathrm{bcd}$ & $37.8 \mathrm{bc}$ & $21.2 \mathrm{c}$ & $35.1 \mathrm{bc}$ & $6.7 \mathrm{~b}$ & $6.5 \mathrm{ab}$ \\
\hline 10. Control & $4.4 \mathrm{e}$ & $5.6 \mathrm{~d}$ & $5.2 \mathrm{~d}$ & $9.2 \mathrm{~d}$ & $5.3 \mathrm{~d}$ & $6.7 \mathrm{ab}$ \\
\hline LSD $(0.05)$ & 11.0 & 14.0 & 10.0 & 22.3 & 0.8 & 1.3 \\
\hline Contrasts & & & & & & \\
\hline $\begin{array}{l}\text { Pollenizer }(1,2,3,4,5,6,7,8,9) \\
\quad \text { versus no pollenizer }(10)\end{array}$ & $* * * \mathrm{v}$ & $* * *$ & $* * *$ & $* * *$ & $* * *$ & NS \\
\hline $\begin{array}{l}\text { Individual }(1,3,4) \text { versus } \\
\text { combined }(5,6,7)\end{array}$ & NS & NS & NS & NS & NS & NS \\
\hline Mickylee (2) versus combined $(5,6,7)$ & NS & NS & NS & NS & NS & $*$ \\
\hline $\begin{array}{l}\text { Companion alone }(1) \text { versus } \\
\text { Companion combined }(5,6)\end{array}$ & $*$ & $* *$ & $* * *$ & NS & $* *$ & NS \\
\hline $\begin{array}{l}\text { SP1 alone }(3) \text { versus SP1 } \\
\text { combined }(5,7)\end{array}$ & NS & NS & NS & NS & NS & NS \\
\hline $\begin{array}{l}\text { SF800 alone }(4) \text { versus SF800 } \\
\text { combined }(6,7)\end{array}$ & NS & NS & NS & $*$ & NS & NS \\
\hline $\begin{array}{l}\text { SF800; Interplanted (4) versus } \\
\quad \text { hill-planted (9) }\end{array}$ & NS & $*$ & $* * *$ & NS & NS & NS \\
\hline $\begin{array}{l}\text { SP1; } 0(3) \text { versus } 3 \text { weeks after } \\
\text { triploid planting }(8)\end{array}$ & $* * *$ & NS & $* * *$ & NS & NS & NS \\
\hline
\end{tabular}

${ }^{\mathrm{z}}$ Cumulative weight of fruit less than $3.6 \mathrm{~kg}$.

${ }^{\mathrm{y}}$ Cumulative weight of fruit between 3.6 and $7.3 \mathrm{~kg}$.

${ }^{\mathrm{x}}$ Cumulative weight of fruit greater than $7.3 \mathrm{~kg}$.

${ }^{\mathrm{w}}$ Any two means within a column followed by the different letters are significantly different

${ }_{\mathrm{NS}}, *, * *, * * *$ Nonsignificant or significant at the $5 \%, 1 \%$, and $0.01 \%$, respectively.

$\mathrm{LSD}=$ least significant difference.

Table 3. Effect of different diploid watermelon pollenizer treatments on percentage of marketable fruit. ${ }^{z}$

\begin{tabular}{llr}
\hline & \multicolumn{2}{c}{ Marketable fruit (\%) } \\
\cline { 2 - 3 } Treatment & \multicolumn{1}{c}{2005} & 2006 \\
\hline 1. Companion & $75.6 \mathrm{bc} \mathrm{b}^{\mathrm{yx}}$ & $93.2 \mathrm{a}$ \\
2. Mickylee & $93.3 \mathrm{ab}$ & $93.3 \mathrm{a}$ \\
3. Super Pollenizer 1 (SP1) & $86.7 \mathrm{abc}$ & $77.8 \mathrm{a}$ \\
4. Summer Flavor 800 (SF800) (interplanted) & $97.8 \mathrm{a}$ & $82.2 \mathrm{a}$ \\
5. Companion and SP1 & $97.8 \mathrm{a}$ & $86.7 \mathrm{a}$ \\
6. Companion and SF800 & $91.1 \mathrm{ab}$ & $82.2 \mathrm{a}$ \\
7. SF800 and SP1 & $86.7 \mathrm{abc}$ & $84.4 \mathrm{a}$ \\
8. SP1 (late planting) & $48.9 \mathrm{~d}$ & $53.3 \mathrm{~b}$ \\
9. SF800 (hill-planted) & $88.9 \mathrm{ab}$ & $91.1 \mathrm{a}$ \\
10. Control & $67.3 \mathrm{~cd}$ & $34.4 \mathrm{~b}$ \\
LSD (0.05) & 21.4 & 24.3
\end{tabular}

Contrasts

Pollenizer $(1,2,3,4,5,6,7,8,9)$ versus no pollenizer (10)

Individual $(1,3,4)$ versus combined $(5,6,7)$

Mickylee (2) versus combined $(5,6,7)$

Companion alone (1) versus Companion combined $(5,6)$

SP1 alone (3) versus SP1 combined $(5,7)$

SF800 alone (4) versus SF800 combined $(6,7)$

SF800; Interplanted (4) versus hill-planted (9)

SP1; 0 (3) versus 3 weeks after triploid planting (8)

$* \mathrm{w} \quad * * *$

${ }^{\mathrm{z}}$ Marketable fruit included fruit $\geq 3.6 \mathrm{~kg}$ with no hollow heart (rating 0 ) or minimal hollow heart, width less than $0.6 \mathrm{~cm}$, depth less than $1.3 \mathrm{~cm}$ (rating 1), and width $\geq 0.6 \mathrm{~cm}<3.3 \mathrm{~cm}$, depth $\geq 1.3 \mathrm{~cm}<5.1 \mathrm{~cm}$ (rating 2), see Figure 2 in text.

$y_{\text {i.e., }} 75.6 \%$ of fruit is marketable with no or minimal hollow heart, $24.4 \%$ of fruit is not marketable due to severe hollow heart.

${ }^{\mathrm{x}}$ Any two means within a column followed by different letters are significantly different.

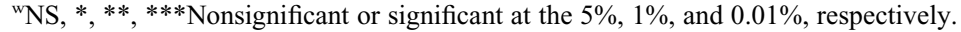

$\mathrm{LSD}=$ least significant difference.

both treatments had similar yields (data not shown). In 2006, no differences were found between the two treatments for any of the harvests. 'SP1' resulted in higher early yields, whereas the later planting of 'SP1' tended to produce better yields at later harvests.
Timing of 'SP1' transplanting influenced hollow heart. In 2005, when 'SP1' was planted at the same time as the triploid plants, $86.7 \%$ of the fruit was marketable compared with $48.9 \%$ for the late planting (Table 3). In 2006, the early and late planting had $77.8 \%$ and $53.3 \%$ marketable fruit, respectively, with minimal or no hollow heart. In both years, the later 'SP1' planting produced fruits with a similar percentage of marketable sized fruit with severe hollow heart compared with the no pollenizer treatment.

\section{Discussion}

Year had a large effect on the time period in which watermelon fruit were set. In 2005, fruit set was concentrated with two harvests 1 week apart, whereas in 2006, four harvests were over a 4-week period. Variations in fruit set may occur for several reasons. Environment has a large effect on fruit set. For example, rainy or cool weather can hinder bee activity and reduce the quality or quantity of fruit. Reduction in the number of bee visits has resulted in lower yields and fruit quality in watermelon (Adlerz, 1966; Stanghellini et al., 1997; Walters, 2005). In 2006, bee activity in two hives was limited during the first 6 weeks of fruit set and may have extended duration of fruit set in 2006 stretching the time required for the triploid vines to reach maximum fruit load. Walters and Taylor (2006) reported that pumpkin yields were increased when more bee hives were used, but there are no reports to determine the number of honeybee hives or bees necessary to maximize fruit yields and quality in triploid watermelon.

Results indicated that a viable pollen source was needed because 'TriX-313' fruit set and yield was limited in the no pollenizer treatment. However, those treatments had less than $10 \%$ and $22 \%$ early and total yield, respectively, compared with other treatments that had a pollenizer. There was obviously some pollen movement between plots, but the effects on 'Tri-X-313' yield and fruit quality were attributed to pollenizer treatment differences, especially during early harvests. Furthermore, many of the fruit that set in the no pollenizer treatment had inferior quality with $\approx 50 \%$ of the fruit having severe hollow heart. Fiacchino and Walters (2003) indicated that hollow heart could be more prevalent when certain cultivars are used as pollenizers. It appears that the limited amount of pollen in the no pollenizer treatment may have contributed to increased severe hollow heart in triploid watermelon.

The use of a single pollenizer cultivar is an effective pollenizer strategy for producing triploid fruit. Certain cultivars were better than others, and results were sometimes variable among plantings. The use of cultivars developed exclusively as pollenizers and the open-pollinated cultivar Mickylee consistently produced better total and marketable weight than 'SF800'. 'Mickylee' has been on the market for a long time (Maynard, 2003) and is an effective pollenizer. Its use has 
resulted in triploid yields similar to triploid yields obtained with the specialized pollenizer cultivars (Freeman et al., 2007a). The newer pollenizer cultivars have been intentionally developed strictly as pollen sources for triploid fruit production rather than production and sale of the diploid fruit.

An early triploid fruit harvest likely occurs when using 'Companion' as the pollenizer because it has higher counts of staminate flowers earlier in the season (Dittmar et al., 2009). Later harvests of triploid fruit can be increased if another pollenizer that flowers later is planted with 'Companion'. Thus, 'Companion' is most complimented by a late-flowering pollenizer. 'SP1' provided minimal improvement or increase in yields when combined with the other pollenizers. Shortly after staminate flowers were produced by 'Companion', 'SP1' consistently produced a higher number of staminate flowers over a longer time period compared with the other cultivars (Dittmar et al., 2009; Freeman and Olson, 2007). Thus, 'SP1' is likely providing ample amounts of the pollen during most of the production season. Lower triploid yields were obtained with 'SF800' rather than combining 'SF800' with 'Companion' or 'SP1'. It would probably be better to choose and use single pollenizers that improve triploid yields than complicate planting by using two pollenizers.

'SF800' hill-planted had one fourth less fruit than the interplanted treatment in 2005. This likely occurred because there were one fourth less plants for triploid fruit production with the hill-planting arrangement as reported by NeSmith and Duval (2001). In the 2006 study, yields were equivalent with these same treatments. The reason that no yield gain was realized with the interplanted 'SF800' versus the hill-planted 'SF800' treatment in 2006 like in 2005 is unclear. Reducing the inrow spacing decreases the size of the watermelon fruit (Duthie et al., 1999a, 1999b; Motsenbocker and Arancibia, 2002; NeSmith, 1993). In our studies, triploid fruit size was unaffected by less spacing between plants (interplanting) compared with hill planting.

The purpose of planting the 'SP1' plants 3 weeks after the triploid plants was to decrease the incidence of hollow heart in the triploid fruit, especially because hollow heart is more prevalent in the crown set (Maynard and Hopkins, 1999). However, we found hollow heart to be more extensive in the late planting of 'SP1', and yields were lower with later pollenizer planting. Planting the 'SP1' plants 3 weeks after transplanting the triploid plants was too late because triploid vine growth was extensive by the time 'SP1' was transplanted. The establishment of pollenizer transplants from ' $\mathrm{SP} 1$ ' and other pollenizer cultivars should be made closer to the time when the triploid plants are transplanted (i.e., 1 or 2 weeks after planting) when the triploid plants have less vegetation and growth to possibly gain any yield or quality advantage.

In addition to yield, fruit quality is an important consideration, especially hollow heart. Severe hollow heart caused as many as $67 \%$ of the fruit to be nonmarketable in the control treatment compared with as few as $2 \%$ of the fruit being nonmarketable in the 'SF800' pollenizer treatment. When pollenizer plants were transplanted at the same time as the triploid plants, the percentage of nonmarketable fruit caused by hollow heart ranged from $2 \%$ to $22 \%$ among treatments. Although these percentages are considerably lower than the control, there were differences in the amount of hollow heart as a result of which pollenizer was chosen. Subsequent research should focus more on the effects of the pollenizer on hollow heart.

\section{Summary}

The use of dedicated pollenizers 'Companion' and 'SP1' resulted in better triploid watermelon yields than 'SF800'. Similar triploid watermelon yields were obtained with 'Companion', 'SP1', and 'Mickylee' pollenizers. Unlike 'Companion' and 'SP1', 'Mickylee' and 'SF800' both have the advantage of producing marketable seeded fruits that provide potential additional revenue. If a pollenizer that results in high yields of triploid fruits is chosen, then combining two different pollenizers does not increase yields of triploid fruit and complicates planting as a result of the additional care that needs to be taken to ensure that the two pollenizers are planted properly. The use of interplanting a pollenizer improved yields compared with hill-planting when fruit set was more concentrated and had minimal effect on fruit size. Transplanting the pollenizer 3 weeks after the triploid plants were transplanted is not recommended. 'SF800' produces an aggressive, vigorous vine (Dittmar et al., 2009) and likely had competitive effects, which reduced yields of triploid fruits. It should be noted that high yields of diploid fruit were produced from 'SF800' interplanted resulting in production of potentially more marketable fruit than if a pollenizer was chosen as only a viable pollen donor (data not presented). The use of marketable pollenizers like 'Mickylee' or 'SF800' might be an excellent option for growers who can market diploid watermelons.

\section{Literature Cited}

Adlerz, W.C. 1966. Honey bee visit number and watermelon pollination. J. Econ. Entomol. 59:28-30.

Dittmar, P.J., D.W. Monks, and J.R. Schultheis. 2009 Vegetative, floral, and fruit characteristics of watermelon pollenizers. HortScience 44:59-63.

Duthie, J.A., B.W. Roberts, J.V. Edelson, and J.W Shrefler. 1999a. Plant density-dependent variation in density, frequency, and size of watermelon fruits. Crop Sci. 39:412-417.
Duthie, J.A., J.W. Shrefler, B.W. Roberts, and J.V. Edelson. 1999b. Plant density-dependent variation in marketable yield, fruit biomass, and marketable fraction in watermelon. Crop Sci. 39:406-412.

Fiacchino, D.C. and S.A. Walters. 2003. Influence of diploid pollenizer frequencies on triploid watermelon quality and yields. HortTechnology 13:58-61.

Freeman, J.H., G.A. Miller, S.M. Olson, and W.M. Stall. 2007a. Diploid watermelon pollenizer cultivars differ with respect to triploid watermelon yield. HortTechnology 17:518-522.

Freeman, J.H., S.M. Olson, and W.M. Stall. 2007b. Competitive effect of in-row diploid watermelon pollenizers on triploid watermelon yield. HortScience 42:1575-1577.

Freeman, J.H. and S.M. Olson. 2007. Characteristics of watermelon pollenizer cultivars for use in triploid production. Intl. J. of Vegetable Prod. 13:73-80.

Kihara, H. 1951. Triploid watermelons. Proc. Amer. Soc. Hort. Sci. 58:217-230.

Maynard, D.N. 2003. New plants for Florida: Watermelon. In: Jones, R.I., M Durya, and B.J. Treat (eds.). Circular 1440.

Maynard, D.N. and G.W. Elmstrom. 1990. Pollenizers affect fruit set, frequency of hard seeds, and yield of triploid watermelon. XXIII Intl. Hort. Cong. Abstracts of Contributed Papers $1: 445$.

Maynard, D.N. and D.L. Hopkins. 1999. Watermelon fruit disorders. HortTechnology 9:155-161.

Motsenbocker, C.E. and R.A. Arancibia. 2002. Inrow spacing influences triploid watermelon yield and crop value. HortTechnology 12:437440.

NeSmith, D.S. 1993. Plant spacing influences watermelon yield and yield components. HortScience 28:885-887.

NeSmith, D.S. and J.R. Duval. 2001. Fruit set of triploid watermelons as a function of distance from a diploid pollenizer. HortScience 36:60-61.

Robinson, R.W. and D.S. Decker-Walters. 1997. Cucurbits. CAB Intl., New York, NY.

Rubatzky, and Yamaguchi. 1997. World vegetables. 2nd Ed. Chapman \& Hall Publ., New York, NY.

Sanders, D.C. (ed.). 2004. Vegetable crop handbook for the southeastern U.S. 2003-2004. Vance Publishing Corp., Lincolnshire, IL.

Sanders, D.C. (ed.). 2005. Vegetable crop handbook for the southeastern U.S. 2004-2005 Vance Publishing Corp., Lincolnshire, IL.

SAS Institute. 2002. SAS for Windows. Release 9.1. SAS Inst., Cary, NC.

Stanghellini, M.S., J.T. Ambrose, and J.R. Schultheis. 1997. The effects of honey bee and bumble bee pollination on fruit set and abortion of cucumber and watermelon. Amer. Bee J. 137: 386-391.

U.S. Department of Agriculture. 2006. United States standards for grades of watermelons. USDA, Washington, DC.

U.S. Department of Agriculture, Economic Research Service. 2005. Vegetables and melons outlook/VGS-308/21 Apr. 2005. p. 11.

Walters, S.A. 2005. Honey bee pollination requirements for triploid watermelon. HortScience 40:1268-1270.

Walters, S.A. and B.H. Taylor. 2006. Effects of honey bee pollination on pumpkin fruit and seed yield. HortScience 41:370-373. 